\title{
PERAN KAPABILITAS INTERAKSI DAN KREASI NILAI BERSAMA UNTUK MENINGKATKAN KINERJA PEMASARAN
}

\author{
Ken Sudarti* \\ Universitas Islam Sultan Agung Semarang, Indonesia \\ Okky Wardhiani \\ Universitas Islam Sultan Agung Semarang, Indonesia
}

\begin{abstract}
This study focuses on the role of Individual and Relational Interaction Capability in increasing Emotional and Social Value Co-Creation on Market Performance in beauty salon services. Value CoCreation is one of the service organization's strategies in utilizing external resources from customers. This strategy is crucial because the performance of service organizations is mostly determined by the ability of the fronline staff who interact with customers during service meetings. This research belongs to explanatory research with a population of beauty salon customers in Central Java. The sample consisted of 203 customers, and it was determined using the purposive sampling technique. The author collects customer data through the distribution of offline and online questionnaires analyzed using SPSS 23.0-based regression. This study has proven that Emotional and Social Value Co-Creation can mediate between Individual and Relational Capability with Market Performance. Emotional and social values that are created together will be beneficial for the parties involved. For customers, interactions during the value co-creation process will increase their satisfaction because it can fulfill their needs and desires. This study has also shown the role of individual and relational capability in increasing customer willingness to engage in mutual value creation interactions.
\end{abstract}

JEL : D20, L10, M20.

Keywords : individual interaction capability, relational interaction capability, emotional value cocreation, social value co-creation, market performance.

\begin{abstract}
ABSTRAK
Studi ini fokus pada peran Individual dan Relational Interaction Capability dalam meningkatkan Emotional dan Social Value Co-Creation menuju Market Performance pada jasa salon kecantikan. Value Co-Creation merupakan salah satu strategi organisasi jasa dalam memanfaatkan sumberdaya eksternal yang berasal dari pelanggan. Strategi ini sangat penting karena performa organisasi jasa sangat ditentukan oleh kemampuan fronline staff dalam berinteraksi dengan pelanggan pada saat pertemuan jasa. Jenis penelitian bersifat explanatory research dengan populasi pelanggan salon kecantikan di Jawa Tengah. Ukuran sampel yang digunakan sebanyak 203 pelanggan. Teknik pengambilan sampel menggunakan purposive sampling. Peneliti mengumpulkan data pelanggan melalui penyebaran kuisioner secara offline dan online. Alat analisis data menggunakan regresi berbasis SPSS 23.0. Studi ini telah berhasil membuktikan bahwa Emotional dan Social Value CoCreation mampu memediasi antara Individual dan Relational Capability dengan Market Performance Nilai emosional dan sosial yang dikreasikan bersama akan bermanfaat bagi pihak-pihak yang terlibat. Bagi pelanggan, interaksi selama proses value co-creation akan meningkatan kepuasannya karena kebutuhan dan keinginannya dapat terpenuhi. Studi ini juga telah membuktikan peran individual dan relational capability dalam meningkatkan keinginan pelanggan terlibat dalam interaksi penciptaan nilai bersama.
\end{abstract}

Kata Kunci : individual interaction capability, relational interaction capability, emotional value cocreation, social value co-creation, market performance.

\footnotetext{
*Email : kensudarti@unissula.ac.id

Received : 20-03-2021, Accepted : 07-12-2021, Published : 28-12-2021

P-ISSN : 2087-9954, E-ISSN : 2550-0066. DOI : http://dx.doi.org/10.26418/jebik.v10i3.45790
} 


\section{PENDAHULUAN}

Salon kecantikan merupakan bagian dari industri jasa kreatif yang akan terus mengalami perkembangan. Selama ini industri salon menjadi bagian industri kreatif yang menunjang industri kosmetik, fashion, dan seni menyebabkan banyak munculnya bisnis salon kecantikan mulai dari yang kecil hingga besar. Sedikitnya, 101 ribu salon di Indonesia beroperasi dengan estimasi jumlah karyawan yang terserap lebih dari 500 ribu orang membuat persaingan bisnis salon menjadi lebih ketat dibanding era sebelumnya (Mutiah, 2020). Persaingan yang semakin ketat mengharuskan perusahaan salon untuk mengelola semua sumber daya yang ada secara optimal agar dapat bertahan di dunia usaha yang selalu mengalami perubahan dengan cepat. Oleh karena itu perlu adanya perubahan strategi salon kecantikan agar tetap memiliki daya saing kompetitif (Maulina \& Sari, 2017). Strategi pemasaran jasa tidak dapat dipisahkan dari 4 (empat) karakteristik yang melekat pada jasa yang membedakannya dengan barang diantaranya adalah tidak berwujud (Intangibility), tidak dapat dipisahkan (Inspirability), berubah-ubah (Variability), dan mudah lenyap (Perishability) (Tjiptono, 2005). Nilai jual yang unik dari layanan adalah esensi penting pada karyawan untuk terlibat secara langsung dalam proses interaksi jasa, sehingga karyawan memiliki pengaruh dalam kesuksesan perusahaan jasa.

Strategi pemasaran jasa yang baik adalah ketika jasa yang ditawarkan dapat memuaskan pelanggannya. Hal ini dapat dicapai dengan memberikan kualitas layanan yang fit dengan kebutuhan pelanggan, dapat dinikmati, dan nyaman. Pelanggan salon akan puas ketika interaksi dengan karyawan dapat meningkatkan rasa nyaman dan citra dirinya. Menurut Zhang, Jahromi, \& Kizildag (2018) setiap calon pembeli berusaha untuk mencari tahu mengenai kualitas sebuah jasa beserta beberapa informasi tambahan seperti: harga, fasilitas, pelayanan karyawan yang ramah ketika bertukar sapa. Jika semua itu diperoleh konsumen, maka dengan senang hati mereka memberikan rekomendasi kepada orang lain. Oleh karena itu, menciptakan interaksi yang baik dengan pelanggan serta meningkatkan kemampuan karyawan dalam melakukan interaksi menjadi faktor yang sangat krusial.

Penelitian ini menguji pengaruh individual dan relational interaction capability dalam meningkatkan value co-creation dan market performance khususnya pada jasa salon kecantikan. Penelitian ini dilakukan karena masih ada perbedaan hasil penelitian, dimana Vargo \& Lusch (2004) menyatakan bahwa value co creation tercipta ketika perusahaan mampu memanfaatkan sumberdaya eksternal, namun hasil penelitian Grönroos \& Ravald (2011) menyatakan bahwa, value co creation tidak selalu muncul dalam interaksi pelanggan dan penyedia jasa. Lingkungan bisnis yang bersifat dinamis, membuat perusahaan menerapkan individual interaction capability yaitu kemampuan karyawan dalam memahami keinginan tiap pelanggan. Selain itu, relational interaction capability memiliki peran penting selama penyampaian jasa. Kedua kemampuan itu akan menciptakan pengalaman baru bagi pelanggan dan mempengaruhi intensitas keterlibatannya dalam kreasi nilai bersama (Ramaswamy \& Ozcan, 2018). Munculnya nilai interaktif adalah ketika nilai dilakukan oleh dua orang atau lebih dimana pelanggan sebagai innovator (Franke \& Piller, 2004; Syam \& Pazgal, 2013).

Hasil studi ini akan melengkapi studi sebelumnya tentang implementasi value co-creation pada jenis jasa yang berbeda, yaitu jasa salon kecantikan. Bukti empiris implementasi value cocreation yang berasal dari beberapa jasa akan semakin menguatkan konsep Service Dominan Orientation (SDO) yang dikemukakan oleh Vargo \& Lusch (2014). Nilai yang dikreasikan bersama selanjutnya akan bermanfaat bagi pihak-pihak yang terlibat. Bagi pelanggan, interaksi selama 
proses value co-creation akan meningkatan kepuasannya karena kebutuhan dan keinginannya dapat terpenuhi. Demikian juga bagi karyawan, interaksi selama proses value co-creation akan menambah pengetahuannya tentang bagaimana menyediakan layanan yang lebih fit dengan tuntutan pelanggan. Hal ini diyakini akan berdampak pada meningkatnya marketing performance.

\section{KAJIAN PUSTAKA}

\subsection{Individual Interaction Capability}

Individual interaction merupakan variasi penawaran yang diinginkan pelanggan tanpa mengurangi kebutuhan pelanggan sebelumnya (Forza \& Salvador, 2002). Individual interaction merupakan sebuah kajian mengenai fenomena subjektif dalam konteks yang dirasakan pelanggan dan dipengaruhi lingkungan bisnis yang sesuai dengan keinginan pelanggan. Hal ini berkaitan dengan pelanggan yang memiliki keinginan unik dan bervariasi, sehingga mengharuskan karyawan memberikan perhatian dan pelayanan secara lebih privasi pada setiap pelanggan.

Capability merupakan kemampuan fisik dan mental karyawan dalam melakukan suatu pekerjaan secara maksimal (Kreitner \& Angelo, 2003). Untuk mencapai pekerjaan maksimal maka setiap karyawan harus memperhatikan ketrampilan, prosedur, proses yang spesifik agar dapat dimanfaatkan sebagai sumber daya unggul dan kompetitif (Baker \& Sinkula, 2005). Hogel \& Brown (2005) menyatakan bahwa capability merupakan kemampuan memobilisasi sumber daya baik dalam wujud fisik (tangible resource) maupun non fisik (intangible resource), seperti: talenta, jejaring, kerja sama, finansial, dan fisik agar dapat menghasilkan nilai yang lebih unggul.

Individual Interaction Capability (IIC) diartikan sebagai kemampuan karyawan dalam memahami proses integrasi sumber daya dalam sistem pelayanan sehingga hasil layanan seperti diinginkan setiap pelanggan (Karpen, Bove, Lukas \& Zyphur, 2015). Kemampuan ini memungkinkan perusahaan agar lebih mengantisipasi dan merasakan keadaan mitra yang bersifat unik, sehingga value co-creation difasilitasi sebagai solusi agar barang atau jasa yang ditawarkan sesuai dengan kondisi tiap mitra. Individual Interaction Capability (IIC) merupakan kemampuan karyawan untuk memahami rutinitas operasi saat menghadapi perubahan lingkungan bisnis sesuai dengan keinginan tiap konsumen agar mencapai efektivitas yang lebih baik. Karpen et al. (2015) menggunakan indikator-indikator berikut ini untuk mengukur individual interaction capability, yaitu: kemampuan karyawan dalam memahami kebutuhan pelanggan secara personal, kemampuan karyawan memahami sensitivitas situasi pribadi pelanggan, kemampuan karyawan dalam mengidentifikasi harapan pribadi tiap pelanggan dan kemampuan karyawan memahami jenis penawaran yang sangat membantu pelanggan.

\subsection{Relational Interaction Capability}

Relational Interaction Capability (RIC) merupakan kemampuan karyawan dalam meningkatkan hubungan sosial dan emosional pada konsumen dalam sistem layanan (Karpen et al., 2015). Kemampuan ini dapat menjadikan perusahaan menjadi lebih baik, karena kemampuan karyawan membangun interaksi selama proses konsumsi dengan pelanggan membuat karyawan dapat merasakan keadaan pelanggan sesungguhnya dan mengetahui ekspektasi pelanggan terhadap perusahaan. Nilai yang dikreasikan bersama antara karyawan dan pelanggan akan menjadi solusi yang dapat ditawarkan kepada pelanggan secara lebih personal. Sambyal, Saini \& Syal (2020) mendefinisikan relational interaction capability sebagai kemampuan perusahaan menciptakan sesuatu dengan menjalin kerjasama melalui tindakan menghubungan interaksi emosional dan 
sosial pada pelanggan. Tindakan kerjasama akan terjalin dengan baik dan berdampak pada ketangkasan dalam meningkatkan pelayanan untuk pelanggan.

Berdasarkan uraian di atas dapat disimpulkan bahwa Relational Interaction Capability (RIC) merupakan kemampuan karyawan dalam membangun, meningkatkan dan mempertahankan keakraban dengan konsumen agar terjadi kedekatan dalam mengelola hubungan dengan konsumen yang saling menguntungkan. Indikator relational interaction capability menurut (Karpen et al., 2015), diantaranya; kemampuan karyawan menjalin hubungan dengan pelanggan, kemampuan karyawan menciptakan rasa nyaman selama proses transaksi, minat yang tulus karyawan, ketika melibatkan pelanggan dan kemampuan karyawan mendorong komunikasi dua arah dengan pelanggan.

\subsection{Emotional Value Co-creation}

Value co-creation merupakan kolaborasi pengetahuan atau pengalaman pelanggan dengan perusahaan (Payne, Storbacka \& Frow, 2008). Value co-creation menjadikan partisipasi pelanggan sebagai sumber daya pencipta, produsen, dan penguji penggunaan produk atau layanan yang diberikan oleh perusahaan (Pan, 2020). Perusahaan yang menerapkan value co-creation dapat memunculkan nilai emosional pada pelanggan. Menurut Smith \& Colgate (2007), nilai emosional dapat tercipta dengan cara meningkatkan kesenangan, kenikmatan, dan kegembiraan dari suatu pengalaman layanan.

Berdasarkan uraian di atas dapat disimpulkan bahwa Emotional Value Co-Creation (EVC) merupakan utilitas yang dirasakan dan diperoleh pelanggan yang berkaitan dengan munculnya perasaan atau keadaan afektif yang dibentuk melalui proses interaksi pelanggan dengan penyedia layanan (Li, Chan \& Kim, 2019; Sahi, Sekhon \& Quareshi, 2016). Emotional value co-creation merupakan proses interaksi yang dapat menimbulkan perasaan kesenangan, kenikmatan, kenyamanan, kegembiraan dari suatu pengalaman (Smith \& Colgate, 2007). Semua perasaan itu akan membuat pelanggan lebih bersedia berpartisipasi dalam kreasi nilai bersama.

Emotional value co creation merupakan interaksi antara pelanggan dan karyawan dengan mengkolaborasikan nilai pengalaman sebelumnya agar membangkitkan perasaan, sikap, emosi pelanggan pada perusahaan. Mengacu pada penelitian oleh Sahi et al. (2016) dan Li et al. (2019) terdapat 5 indikator dalam emotional value co-creation antara lain: partisipasi pelanggan untuk membantu penyedia layanan menciptakan produk yang lebih aman, partisipasi pelanggan untuk membantu penyedia layanan menciptakan produk baru yang lebih nyaman, partisipasi pelanggan untuk membantu penyedia layanan membuat produk yang lebih membahagiakan, partisipasi pelanggan untuk membantu penyedia layanan membuat produk lebih nikmat, partisipasi pelanggan untuk membantu penyedia layanan membuat produk yang lebih membanggakan.

\subsection{Social Value Co-creation}

Social value co-creation merupakan kolaboratif dari penciptaan nilai sosial antara karyawan dan pelanggan, karena pelanggan bukan hanya berperan sebagai pengguna layanan saja namun sebagai mitra usaha yang ikut berpartisipasi mengembangkan bisnis perusahaan melalui pengalaman sebelumnya ketika menggunakan produk atau layanan yang ditawarkan perusahaan (Buana, Isanawikrama, Hutomo \& Kurniawan, 2019). Menurut Sahi et al. (2016), social value cocreation merupakan utilitas yang dirasakan dan diperoleh dari asosiasi alternatif dengan satu atau lebih kelompok sosial tertentu yang dibentuk melalui proses interaksi pelanggan dengan penyedia 
layanan. Setiap nilai sosial berkaitan dengan pengalaman penggunaan penawaran nilai yang telah disediakan (Payne et al., 2008; Vargo, Lusch, Akaka \& He, 2010). Penawaran nilai sosial diantaranya yaitu merek, penawaran produk dan pengalaman kinerja yang tersedia secara instan (Payne \& Frow, 2013). Grönroos (2008) berpendapat bahwa adanya interaksi selama penggunaan layanan memungkinkan pelanggan berpartisipasi untuk menciptakan nilai pada diri mereka sendiri termasuk saat menggunakan produk yang ditawarkan oleh perusahaan. Oleh karena itu perusahaan memiliki peluang untuk mengembangkan dan menciptakan value co-creation dengan pelanggan.

Berdasarkan uraian di atas dapat disimpulkan bahwa Social Value Co-creation (SVC) merupakan interaksi antara pelanggan dan karyawan dengan mengkolaborasikan nilai pengalaman sosial sebelumnya agar membangkitkan nilai sosial mengenai merk produk atau layanan yang diinginkan pelanggan. Terdapat empat indikator berdasarkan penelitian Sahi et al. (2016) dan Li et al. (2019) diantaranya: partisipasi pelanggan untuk membantu penyedia layanan meningkatkan prestise produk, partisipasi pelanggan untuk membantu penyedia layanan meningkatkan citra merk, partisipasi pelanggan untuk membantu penyedia layanan meningkatkan status pelanggan dan partisipasi pelanggan untuk membantu penyedia layanan meningkatkan citra diri pelanggan.

\subsection{Market Performance}

Market performance merupakan alat ukur bisnis yang digunakan untuk mengukur tingkat keberhasilan suatu perusahaan diantaranya omset penjualan, jumlah pelanggan, penjualan dan profitabilitas pertumbuhan pelanggan (Voss \& Voss, 2000). Market performance merupakan faktor yang digunakan untuk mengukur dampak dari strategi yang diterapkan oleh perusahaan (Ferdinand, 2000). Hal tersebut mengakibatkan strategi perusahaan harus selalu diberikan arahan agar mencapai kinerja pemasaran dan kinerja keuangan yang lebih baik dari sebelumnya.

Market performance merupakan sebuah acuan perusahaan mengenai sejauh mana perusahaan dapat mencapai pasar yang lebih baik daripada pesaingnya, sehubungan dengan reaksi cepat terhadap peluang pasar, kepuasan, retensi pelanggan dan akuisisi pelanggan baru (Homburg \& Jensen, 2007). Selain itu, market performance juga dipandang sebagai respon perilaku pembelian pelanggan dan menjadi prospek target pasar terhadap keunggulan posisi perusahaan yang direalisasikan (Morgan, Slotegraaf \& Vorhies, 2009). Market performance merupakan kunci keberhasilan bisnis selaku hasil dari strategi pasar bagi perusahaan atau organisasi yang mencakup pertumbuhan penjualan, kenaikan pangsa pasar, dan pengembangan pasar (Saeko, Chuntarung \& Thoumrungroje, 2012). Hal ini menandakan bahwa pentingnya setiap perusahaan untuk mengetahui prestasi pasar dari setiap produknya agar menjadi gambaran keberhasilan perusahaan pada persaingan bisnis.

Berdasarkan uraian di atas dapat disimpulkan bahwa Market Performance (MP) merupakan konsep mengukur prestasi pasar dari suatu produk mengenai respon pelanggan terhadap citra dan positioning perusahaan. Setiap perusahaan penting untuk mengetahui prestasi pasar dari produk yang dihasilkan, karena berfungsi sebagai cermin dari keberhasilan usaha dalam persaingan bisnis. Berikut indikator market performance menurut Morgan (2012), diantaranya: kualitas pelayanan yang sesuai dengan harapan pelanggan, kepuasan pelanggan yang meningkat, rekomendasi kepada pihak lain, minat untuk membeli ulang, lebih rendahnya sensitivitas harga dan mendorong teman atau kenalan berbisnis dengan penyedia layanan. 


\subsection{Individual Interaction Capability dan Emotional Value Co-creation}

Sebuah perusahaan yang berorientasi pada pelanggan akan mempertahankan hubungan pelanggan jangka panjang. Untuk mewujudkan tujuan tersebut setiap karyawan harus memiliki kemampuan memahami pelanggan dalam membentuk harapan baru, dengan cara mengikuti arah keinginan pelanggan yang unik agar dapat terjadi penciptaan nilai. Proses penciptaan nilai dapat dilakukan oleh tiap individu melalui pengalaman kreasi bersama agar terjadi penciptaan nilai kolaboratif dengan karyawan (Prahalad \& Ramaswamy, 2000). Hal ini berakibat, karyawan yang memiliki kemampuan interaksi dalam memahami keinginan tiap pelanggan akan mampu mengaplikasikan dengan baik dan benar sehingga menjadi area yang dapat memperluas ruang lingkup penciptaan nilai produk (Prahalad \& Ramaswamy, 2003). Individual interaction capability menyebabkan keberagaman, karena tindakan penciptaan nilai dimodifikasi untuk mewujudkan emotional value co-creation antara karyawan dengan pelanggan. Individual interaction capability menuntun karyawan untuk melakukan pekerjaan secara lebih jelas dan teratur (Ramaswamy \& Ozcan, 2018). Hal tersebut membuat pekerjaan menjadi lebih efisien dan menciptakan rasa kebersamaan antara karyawan kepada pelanggan sehingga dapat menciptakan rasa nyaman dan menyenangkan pada pelanggan ketika berlangsungnya proses penggunaan jasa (Smith \& Colgate, 2007). Karyawan yang memiliki kemampuan memahami kebutuhan pelanggan dengan mengetahui sensitivitas situasi pribadi pelanggan, memahami jenis penawaran yang dapat membantu pelanggan, serta dapat mengidentifikasi harapan pribadi setiap pelanggan (Karpen et al., 2015). Dapat memunculkan partisipasi pelanggan pasca konsumsi dengan memberikan kepercayaan kepada karyawan dan tidak akan ragu untuk memberikan saran mengenai produk yang nyaman, aman, dan nikmat sehingga tercipta layanan yang lebih membanggakan dan membahagiakan bagi pelanggan.

Berdasarkan penjelasan diatas bahwa ketika konsumen mempersepsikan karyawan mempunyai kemampuan dalam memahami interaksi yang ditunjukkan oleh emotional value cocreation maka, konsumen semakin bersedia berpartisipasi dalam membantu karyawan dengan memberikan masukan mengenai produk yang sesuai dengan kebutuhan dan keinginannya. Oleh karena itu, hipotesis yang diajukan adalah:

$\mathrm{H}_{1}$ : Terdapat pengaruh positif antara individual interaction capability dan emotional value cocreation.

\subsection{Individual Interaction Capability dan Social Value Co-creation}

Perusahaan yang mempertahankan hubungan pelanggan jangka panjang akan berusaha memuaskan keinginan pelanggan. Melalui pengalaman layanan jasa, setiap karyawan harus memiliki kemampuan memahami ketika berinteraksi dengan pelanggan agar terjadi penciptaan nilai Bersama (Saarijärvi, Kannan \& Kuusela, 2013). Teori ini menekankan meskipun karyawan memahami keinginan pelanggan, pelanggan tetap akan menjadi penghasil value co-creation dalam proses penyediaan layanan (Vargo \& Lusch, 2004). Hal tersebut dilakukan agar menimbulkan pengalaman inovatif bagi pelanggan mengenai pengalaman layanan jasa yang berkualitas (Angelis, Conti, Cooper \& Gill, 2011; Grönroos, 2008). Social value co-creation dan individual interaction capability, menyebabkan setiap karyawan menerapkan personalisasi layanan dan pengalaman yang tak terlupakan pada pelanggan. Hal ini dilakukan dengan cara menyesuaikan kondisi pelanggan dengan preferensi atau gaya hidup mereka, kemudian mencocokkannya dengan lingkungan perusahaan dan pengalaman karyawan agar kebutuhan pelanggan tetap terpenuhi 
(Hollebeek, Conduit \& Brodie, 2016). Melalui pemahaman bagaimana pelanggan berintegrasi secara unik dalam merasakan pengalaman layanan yang diberikan oleh karyawan dapat membuat produk yang ditawarkan akan menjadi sumber keunggulan kompetitif (Lusch, Vargo \& O'Brien, 2007). Interaction capability bermanfaat bagi perusahaan kecil dengan sumber daya terbatas. Perusahaan kecil dapat mengintegrasikan sumber daya melalui penyediaan layanan dan bekerja sama dengan pelanggan melalui penciptaan nilai bersama (Branimir \& Zelimir, 2012). Logika mengenai individual interaction capability ialah karyawan mengidentifikasi, memahami dan mengelola pengalaman pelanggan. Perusahaan dapat menawarkan proposisi nilai, tetapi dengan cara menilai dirinya sendiri yang dibuat selama berlangsungnya layanan yang implikasinya masih dalam konteks pemangku kepentingan pasar (Frow \& Payne, 2011). Dalam usaha jasa, dasar dari nilai produk atau layanan interaksi merupakan proses menetapkan solidaritas dan perasaan kebersamaan dengan orang-orang (Ikkala \& Lampinen, 2015). Berkaitan dengan social value cocreation dimana pelanggan menginginkan perawatan ekslusif akan berpartisipasi agar layanan yang personal dapat memberikan status prestise dan kemewahan pada produk.

Berdasarkan penjelasan diatas bahwa ketika pelanggan mempersepsikan karyawan mempunyai kemampuan memahami interaksi yang ditunjukkan oleh social value co-creation maka pelanggan semakin bersedia berpartisipasi dalam membantu karyawan dengan memberikan masukan mengenai produk yang sesuai dengan kebutuhan dan keinginannya. Oleh karena itu, hipotesis yang diajukan adalah:

$\mathrm{H}_{2}$ : Terdapat pengaruh positif antara Individual interaction capability dan social value cocreation.

\subsection{Relational Interaction Capability dan Emotional Value Co-creation}

Dasar dari nilai produk dan layanan adalah interaksi sosial dengan membangun solidaritas dan perasaan kebersamaan di antara pelanggan dan karyawan (Ikkala \& Lampinen, 2015). Komunikasi yang lancar dan menyenangkan dapat menghasilkan kesan positif mengenai pengalaman layanan. Pengalaman layanan pelanggan yang positif berhubungan erat dengan interaksi yang menyenangkan antara pelanggan dengan penyedia layanan (Prahalad \& Ramaswamy, 2004). Layanan yang menyenangkan dapat difasilitasi melalui dialog, partisipasi dan keterlibatan pelanggan yang akan menyebabkan terjadinya pertukaran pendapat yang menghasilkan solusi terbaik (Ranjan \& Read, 2016). Setiap pelanggan membutuhkan diskusi dengan karyawan, sehingga karyawan harus dapat membantu dengan memberikan masukan yang tepat melalui percakapan yang menyenangkan dan ramah (Barlow \& Maul, 2000). Menurut VegaVazquez, Revilla-Camacho \& Cossío-Silva (2013) hal tersebut dapat meningkatkan nilai keuntungan pelanggan mengenai emotional value co-creation. Melalui keterlibatan emosional konsumen dengan suatu merek dapat membangkitkan proses penciptaan nilai bersama (Payne, Storbacka, Frow \& Knox, 2009). Manfaat memberikan nilai saat berlangsungnya proses adalah munculnya keunikan dan perasaan nikmat karena pelanggan merasa diistimewakan (Ranjan \& Read, 2016). Relational interaction capability merupakan kemampuan karyawan dalam menjalin hubungan dengan pelanggan (Karpen et al., 2015), agar menciptakan ikatan emosional pada pelanggan seperti perasaan lebih nyaman (Barlow \& Maul, 2000). Selain itu, perasaan betah ketika menikmati pelayanan (Sweeney \& Soutar, 2001), membuat pelanggan tidak akan lebih intensif berpartisipasi dalam memberikan masukan mengenai produk yang aman, nyaman, membahagiakan, serta membanggakan (Sahi et al., 2016). 
Berdasarkan penjelasan diatas bahwa ketika konsumen mempersepsikan karyawan mempunyai kemampuan berinteraksi yang ditunjukkan oleh emotional value co-creation maka konsumen semakin bersedia berpartisipasi dalam membantu karyawan dengan memberikan masukan mengenai produk yang sesuai dengan kebutuhan dan keinginannya. Oleh karena itu, hipotesis yang diajukan adalah:

$\mathrm{H}_{3}$ : Terdapat pengaruh postif Relational interaction capability dan emotional value co-creation.

\subsection{Relational Interaction Capability dan Social Value Co-creation}

Momen penting pada perusahaan jasa yaitu ketika karyawan melayani pelanggan. Oleh karena itu, harus diupayakan agar karyawan memiliki kemampuan menghubungkan pelanggan seperti, melibatkan dalam komunikasi dan memecahkan masalah bersama melalui kegiatan koordinasi (Madhavaram \& Hunt, 2008). Pelanggan yang secara sukarela berpartisipasi dalam social value co-creation tercermin dari antusiasnya dalam memberikan masukan mengenai layanan (Harmeling, Moffet, Arnold \& Carlson, 2017). Merz, He \& Vargo (2009) memandang nilai merek sebagai nilai guna yang dirasa diciptakan dan ditentukan secara kolektif oleh pelanggan. Suatu merek mewakili sejauh mana kemampuan perusahaan dapat menarik pelanggan dan para pemangku kepentingan. Harmeling et al. (2017) berpendapat bahwa masukan dari pelanggan menjadi pertimbangan bagi perusahaan, sehingga pelanggan memiliki potensi sebagai sumber daya berharga untuk perusahaan. Melalui komunikasi antara karyawan dan pelanggan, ide dan informasi dari pelanggan menjadi lebih berbobot, dipercaya dan lebih otentik daripada hanya dari perusahaan (Trusov, Bucklin \& Pauwels, 2009). Proses penciptaaan nilai bersama mengenai suatu merek dapat dirasakan melalui interaksi sosial antara pelanggan dengan karyawan (Vargo \& Lusch, 2016). Interaksi yang menyenangkan antara pelanggan dan karyawan dilakukan selama berlangsungnya proses konsumsi atau proses layanan (Ranjan \& Read, 2016; Vargo, Maglio \& Akaka, 2008). Pelanggan akan melihat dari nilai pakai atau value-in-use yaitu mengevaluasi pengalaman mereka terhadap suatu produk atau layanan di luar atribut fungsional perusahaan dan sesuai dengan motivasi pelanggan (Ranjan \& Read, 2016). Hal ini terjadi karena pelanggan menilai dan menentukan suatu proposisi nilai berdasarkan spesifikasi yang diberikan oleh karyawan (Lusch et al., 2007).

Berdasarkan penjelasan diatas dapat disimpulkan bahwa ketika konsumen mempersepsikan karyawan mempunyai kemampuan berinteraksi yang ditunjukkan oleh social value co-creation maka konsumen semakin bersedia berpartisipasi dalam membantu karyawan dengan cara memberikan masukan mengenai produk yang sesuai dengan kebutuhan dan keinginannya. Oleh karena itu, hipotesis yang diajukan adalah:

$\mathrm{H}_{4}$ : Terdapat pengaruh positif antara relational interaction capability dan social value cocreation.

\subsection{Emotional Value Co-creation dan Market Performance}

Sánchez, Callarisa, Rodriguez \& Moliner (2006) menyatakan bahwa nilai merupakan konsep dinamis yang dapat dirasakan oleh pelanggan diantaranya perasaan terhadap pengalaman layanan pasca konsumsi dapat membentuk dasar nilai emosional yang dirasakan. Nilai emosional merupakan perasaan nikmat, nyaman, betah, dan kesenangan ketika pelayanan yang dilakukan sesuai dengan yang diharapkan pelanggan (Sweeney \& Soutar, 2001). Ketika terjadi kreasi nilai bersama, pelanggan tidak akan segan untuk memberikan pelayanan timbal balik apabila pelayanan 
yang diberikan sesuai dengan apa yang diinginkan (Zhang et al., 2018). Ketika karyawan mampu melakukan pekerjaan dengan baik dan sesuai dengan harapan pelanggan, maka pelanggan akan puas, dan menjadikan perusahaan sebagai prioritas ketika melakukan pembelian ulang. Selain itu pelanggan akan merekomendasikan kepada pihak lain atau teman untuk datang ke perusahaan langganan (Morgan, 2012). Suatu nilai yang ditawarkan oleh perusahaan akan menunjukkan kualitas pengalaman layanan (Aigninger, 2001). Semakin besar nilai yang dirasakan, maka semakin tinggi harga yang bersedia dibayar konsumen pada layanan. Berdasarkan uraian diatas, hipotesis yang diajukan adalah:

$\mathrm{H}_{5}$ : Terdapat pengaruh positif antara emotional value co-creation dengan market performance.

\subsection{Social Value Co-creation dan Market Performance}

Sánchez et al. (2006) mengatakan bahwa nilai pelanggan dirasakan ketika produk suatu layanan sudah dikonsumsi sehingga menambah pengalaman pelanggan pasca konsumsi. Berkaitan dengan social value co-creation yaitu mengenai nilai merk yang telah dikonseptualisasikan sebagai nilai penggunaan dapat dirasakan melalui evaluasi pengalaman pelanggan dari produk atau layanan yang disebabkan oleh merek (Merz et al., 2009; Ramaswamy \& Ozcan, 2018). Hubungan merek dapat mengacu pada pelanggan yang memiliki hubungan interpersonal dalam jaringan sosial dengan pelanggan lain (Harmeling et al., 2017). Pelanggan termasuk dalam jejaring sosial, yaitu mereka bersosialisasi, berinteraksi, dan terhubung dengan orang lain yang kemungkinannya bisa menjadi calon pembeli perusahaan tempat langganan (Payne et al., 2009). Hal ini terjadi karena setiap calon pembeli akan berusaha untuk mencari tahu mengenai kualitas produk melalui harga, fasilitas dan tahapan konsumsi seperti pelayanan karyawan yang ramah ketika bertukar sapa dan dengan senang hati memberikan rekomendasi kepada pelanggan (Zhang et al., 2018). Selain itu, pelanggan memiliki pengetahuan, keterampilan, kreativitas dalam hubungan dengan karyawan. Hal ini dapat menjadi sumber daya bagi perusahaan. Ide pelanggan untuk memiliki sesuatu yang diinginkan membuat karyawan memahami dan menerapkan strategi perusahaan kepada pelanggan (Barney, 2001). Ketika diaplikasikan sesuai dengan penciptaan nilai sosial bersama antara karyawan dengan pelanggan, maka akan lebih mudah mengenali dan meraih strategi peluang bisnis di pasar tempat mereka beroperasi (Lichtenstein \& Lumpkin, 2008). Selain itu, tahap pasca konsumsi pelanggan akan memposting ulasan mengenai pengalaman mereka tentang pelayanan perusahaan yang ramah dan sesuai dengan yang diharapkan. Pelanggan melakukan itu sebagai bentuk penghargaan mereka untuk perusahaan, dan niat pelanggan untuk melakukan layanan kembali di masa depan, serta pelanggan akan merekomendasikan kepada orang lain apabila pelayanan yang diberikan perusahaan berdampak positif (Zhang et al., 2018). Jadi, hipotesis yang diajukan adalah:

$\mathrm{H}_{6}$ : Terdapat pengaruh positif relational interaction capability dengan social value co-creation.

\subsection{Model Empirik Penelitian}

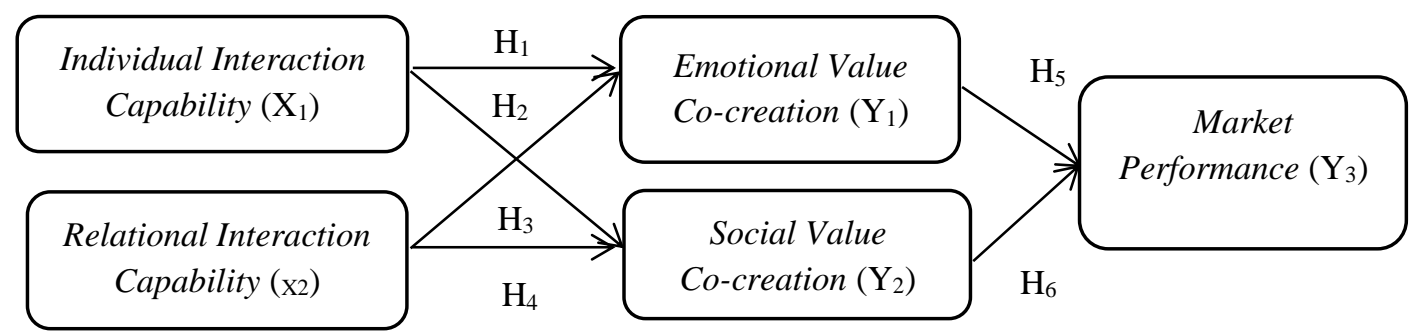

Gambar 1. Kerangka Penelitian 


\section{METODE PENELITIAN}

\subsection{Populasi dan Sampel}

Populasi dalam penelitian ini, adalah pelanggan salon di Jawa Tengah. Munculnya keterbatasan yang dihadapi peneliti akibat jumlah populasi yang banyak, sehingga teknik sampling yang dipilih adalah non probability sampling memungkinkan peluang setiap sampel yang dipilih tidak dikonfirmasi atau tidak diketahui (Rahi, 2017). Purposive Sampling digunakan sebagai teknik pengambilan sampel, dimana sampel penelitian ini merupakan pelanggan salon yang memiliki kriteria: pendidikan minimal SMA, usia minimal 16 tahun, dan minimal sudah 3 kali menggunakan jasa salon yang sama. Penentuan ukuran sampel sesuai rekomendasi (Hair, Black, Babin, Anderson \& Tatham, 2006) bahwa ukuran sampel yang baik adalah 5 kali indikator. Jumlah indikator dalam penelitian ini adalah 23, sehingga ukuran sampel minimal adalah 115. Namun, untuk menghindari adanya data yang tidak lengkap, maka telah disebarkan kuesioner sebanyak 2 (dua) kalinya, yaitu sebesar 230, namun yang memenuhi kriteria berdasarkan kelengkapan data, maka sampel pada penelitian ini sebanyak 203 pelanggan salon.

\subsection{Metode Pengumpulan Data}

Data dalam penelitian ini diperoleh dengan menggunakan kuisioner yang disebarkan secara online kepada pelanggan salon di Jawa Tengah. Kuesioner dirancang dengan menggunakan skala Likert atau Likerts Summated Ratings (LSR) 1 sampai 10 dengan pilihan jawaban dari Tidak Setuju sampai Sangat Setuju (Ghozali, 2008).

\subsection{Teknik Analisis}

Alat analisis yang digunakan dalam penelitian ini adalah regresi dengan menggunakan bantuan software SPSS untuk mengetahui hubungan antara variabel dependen dan independen.

\section{HASIL DAN PEMBAHASAN}

\subsection{Uji Validitas}

Tabel 1. Hasil Uji Validitas Data

\begin{tabular}{|c|c|c|}
\hline Indikator & $\begin{array}{c}\text { Corrected } \\
\text { Item-Total } \\
\text { Correlation }\end{array}$ & p-value \\
\hline \multicolumn{3}{|l|}{ Individual Interaction Capability } \\
\hline $\begin{array}{l}\text { a. Kemampuan karyawan dalam memahami kebutuhan pelanggan secara } \\
\text { lebih privat }\end{array}$ & 0.719 & 0.000 \\
\hline $\begin{array}{l}\text { b. Kemampuan karyawan memahami sensitivitas situasi pribadi } \\
\text { pelanggan }\end{array}$ & 0.722 & 0.000 \\
\hline $\begin{array}{l}\text { c. Kemampuan karyawan dalam mengidentifikasi harapan pribadi tiap } \\
\text { pelanggan }\end{array}$ & 0.803 & 0.000 \\
\hline $\begin{array}{l}\text { d. Kemampuan karyawan memahami jenis penawaran yang sangat } \\
\text { membantu pelanggan }\end{array}$ & 0.824 & 0.000 \\
\hline \multicolumn{3}{|l|}{ Relational Interaction Capability } \\
\hline a. Kemampuan karyawan menjalin hubungan dengan pelanggan & 0.838 & 0.000 \\
\hline $\begin{array}{l}\text { b. Kemampuan karyawan menciptakan rasa nyaman selama proses } \\
\text { tranksaksi }\end{array}$ & 0.852 & 0.000 \\
\hline c. Minat yang tulus karyawan ketika melibatkan pelanggan & 0.880 & 0.000 \\
\hline $\begin{array}{l}\text { d. Kemampuan karyawan mendorong komunikasi dua arah dengan } \\
\text { pelanggan }\end{array}$ & 0.838 & 0.000 \\
\hline
\end{tabular}


Emotional Value Co-creation

a. Partisipasi pelanggan untuk membantu penyedia layanan salon $\quad 0.883 \quad 0.000$ menciptakan produk yang lebih aman ketika digunakan

b. Partisipasi pelanggan untuk membantu penyedia layanan

$0.891 \quad 0.000$

menciptakan produk baru yang lebih nyaman digunakan

$\begin{array}{lll}\text { c. Partisipasi pelanggan untuk membantu penyedia layanan membuat } & 0.925 & 0.000 \\ \text { produk yang lebih membahagiakan }\end{array}$ produk yang lebih membahagiakan

d. Partisipasi pelanggan untuk membantu penyedia layanan membuat $\quad 0.939 \quad 0.000$ produk lebih nikmat ketika digunakan

e. Partisipasi pelanggan untuk membantu penyedia layanan membuat $\quad 0.649 \quad 0.000$ produk yang lebih membanggakan

Social Value Co-creation

a. Partisipasi pelanggan untuk membantu penyedia layanan $0.847 \quad 0.000$ meningkatkan prestise produk

b. Partisipasi pelanggan untuk membantu penyedia layanan $0.923 \quad 0.000$

meningkatkan citra merk
Partisipasi pelanggan untuk membantu penyedia layanan 0.931

$\begin{array}{llllll}\text { meningkatkan status pelanggan } & & & & & \\ \text { Partisipasi pelanggan untuk membantu penyedia layanan } & 0.904 & 0.000\end{array}$

$\begin{array}{lllll}\text { d. Partisipasi pelanggan untuk membantu penyedia layanan } & 0.904 & 0.000 \\ \text { meningkatkan citra diri pelanggan }\end{array}$

Market Performance

a. Kualitas pelayanan yang sesuai dengan harapan pelanggan $\quad 0.860 \quad 0.000$

$\begin{array}{lll}\text { b. Kepuasan pelanggan yang meningkat } & 0.887 & 0.000\end{array}$

$\begin{array}{lll}\text { c. Rekomendasi kepada pihak lain } & 0.901 & 0.000\end{array}$

$\begin{array}{lll}\text { d. Minat untuk membeli ulang } & 0.805 & 0.000\end{array}$

e. Lebih rendahnya sensitivitas harga $\quad 0.817 \quad 0.000$

$\begin{array}{lll}\text { f. Mendorong teman atau kenalan berbisnis dengan penyedia layanan } & 0.858 & 0.000\end{array}$

Pada Tabel 1 diketahui bahwa indikator dari variabel Individual Interaction Capability, Relational Interaction Capability, Emotional Value Co-creation, Social Value Co-creation, dan Market Performance menghasilkan p-value lebih kecil dari taraf signifikansi 0,05. Hal ini dapat diartikan bahwa semua kuesioner dalam penelitian ini telah teruji dengan hasil valid.

\subsection{Uji Reliabilitas}

Tabel 2. Hasil Uji Reliabilitas Data

\begin{tabular}{lcc}
\hline \multicolumn{1}{c}{ Variabel } & Croncbach's Alpha & Keterangan \\
\hline Individual Interaction Capability & 0.726 & Reliabel \\
Relational Interaction Capability & 0.874 & Reliabel \\
Emotional Value Co-creation & 0.915 & Reliabel \\
Social Value Co-creation & 0.923 & Reliabel \\
Market Performance & 0.910 & Reliabel \\
\hline
\end{tabular}

Berdasarkan olah data yang tersaji pada tabel 2, terlihat bahwa semua variabel dalam penelitian ini menghasilkan Cronbach's Alpha lebih besar dari 0,60.

\subsection{Uji Regresi Linier Berganda}

Tabel 3. Hasil Uji Regresi Linier Berganda

\begin{tabular}{|c|c|c|c|c|}
\hline Model & Regresi & $\operatorname{Adj} R^{2}$ & F hitung & p-value \\
\hline 1 & $\mathrm{EVC}=\mathrm{b} 1 \mathrm{IIC}+\mathrm{b} 2 \mathrm{RIC}+\mathrm{e} 1$ & 0.192 & 24.988 & 0.000 \\
\hline 2 & $\mathrm{SVC}=\mathrm{b} 1 \mathrm{IIC}+\mathrm{b} 2 \mathrm{RIC}+\mathrm{e} 2$ & 0.197 & 25.757 & 0.000 \\
\hline 3 & $\mathrm{MP}=\mathrm{b} 3 \mathrm{EVC}+\mathrm{b} 4 \mathrm{SVC}+\mathrm{e} 3$ & 0.262 & 36.856 & 0.000 \\
\hline
\end{tabular}


Berdasarkan olah data yang tersaji pada Tabel 3, terlihat bahwa $p$-value ketiga model regresi telah menunjukkan sig. 0.000 yang berarti bahwa model regresi yang dibuat memiliki goodness of fit yang baik. Pada model pertama didapatkan F hitung sebesar 24.988. Lalu, pada model kedua didapatkan F hitung sebesar 25.757. Sedangkan model ketiga didapatkan F hitung sebesar 36.856. Ketiganya memiliki $F$ hitung yang lebih besar dibandingkan angka pada F tabel yang sebesar 2.42 sehingga dapat disimpulkan bahwa ketiga model tersebut mempunyai pengaruh simultan dan layak untuk digunakan.

\subsection{Uji Hipotesis dan Pembahasan}

Tabel 4. Hasil Uji Hipotesis

\begin{tabular}{ccccccc}
\hline Hipotesis & Regresi & Beta & B & SE & T hitung & p-value \\
\hline $\mathrm{H}_{1}$ & IIC $\rightarrow$ EVC & 0.313 & 0.479 & 0.127 & 3.773 & 0.000 \\
$\mathrm{H}_{2}$ & IIC $\rightarrow$ SVC & 0.329 & 0.420 & 0.106 & 3.974 & 0.000 \\
$\mathrm{H}_{3}$ & RIC $\rightarrow$ EVC & 0.175 & 0.343 & 0.163 & 2.109 & 0.036 \\
$\mathrm{H}_{4}$ & RIC $\rightarrow$ SVC & 0.164 & 0.268 & 0.136 & 1.977 & 0.049 \\
$\mathrm{H}_{5}$ & EVC $\rightarrow$ MP & 0.236 & 0.165 & 0.066 & 2.502 & 0.013 \\
$\mathrm{H}_{6}$ & SVC $\rightarrow$ MP & 0.316 & 0.266 & 0.079 & 3.353 & 0.001 \\
\hline
\end{tabular}

Berdasarkan Tabel 5 dapat diketahui model persamaan regresi linear sebagai berikut :

Model Persamaan 1:

$\mathrm{EVC}=0.313 \mathrm{IIC}+0.175 \mathrm{RIC}+\mathrm{e}$

Berdasarkan output pengelolaan data diatas, diketahui variabel Individual Interaction Capability (IIC) memiliki nilai koofisien beta yang positif sebesar 0.313 artinya jika variabel tersebut meningkat maka variabel dependen (Emotional Value Co-creation) akan meningkat. Nilai signifikasi atau p-value untuk pengaruh secara parsial atau sendiri-sendiri terhadap Emotional Value Co-creation (EVC) adalah sebesar 0.000, artinya lebih kecil dari 0.05 dan nilai nilai t hitung 3,773 yang berarti lebih besar dari t tabel yaitu 1.973, sehingga dapat disimpulkan bahwa terdapat pengaruh variabel independen (IIC) secara parsial terhadap variabel dependen (EVC).

Variabel Relational Interaction Capability (RIC) memiliki nilai koofisien beta yang positif sebesar 0.175 artinya jika variabel tersebut meningkat maka variabel dependen (Emotional Value Co-creation) akan meningkat. Nilai signifikasi atau p-value untuk pengaruh secara parsial atau sendiri-sendiri terhadap Emotional Value Co-creation (EVC) adalah sebesar 0.036, artinya lebih kecil dari 0.05. dan nilai nilai t hitung 2.109 yang berarti lebih besar dari $\mathrm{T}$ tabel yaitu 1.973, sehingga dapat disimpulkan bahwa terdapat pengaruh variabel independen (RIC) secara parsial terhadap variabel dependen (EVC).

Hasil penelitian ini mendukung hasil empirik penelitian sebelumnya seperti (Karpen, Bove \& Lukas, 2012) menunjukkan kemampuan karyawan dalam mengidentifikasi harapan pribadi pelanggan berpengaruh terhadap partisipasi pelanggan menciptakan produk menjadi lebih baik saat digunakan. Ketika pelanggan merasa bahwa karyawan mampu memenuhi harapan pribadinya, maka pelanggan dengan senang hati berpartisipasi untuk menciptakan produk menjadi lebih aman, nyaman, nikmat (Karpen et al., 2015). Oleh karena itu, penting bagi perusahaan salon untuk memelihara tingkat penciptaan nilai emosional dengan pelanggan salon agar meningkatkan pemahaman layanan yang mengarah pada produk lebih membanggakan serta membahagiakan saat digunakan. 
Selain itu, menurut Vargo et al. (2008) bahwa kemampuan karyawan dalam melibatkan komunikasi dua arah, akan mengacu pada partisipasi pelanggan dalam membangun bersama karyawan mengenai produk yang nyaman digunakan. Partisipasi pelanggan dalam menciptakan produk menjadi lebih baik saat digunakan tentunya membuat pelanggan merasa percaya bahwa karyawan mampu memenuhi harapan pribadinya. Hal tersebut, penting bagi perusahaan salon untuk memelihara tingkat penciptaan nilai emosional dengan pelanggan salon agar meningkatkan perasaan nyaman.

Model Persamaan 2:

$\mathrm{SVC}=0.329$ IIC +0.164 RIC $+\mathrm{e}$

Berdasarkan dari hasil pengolahan data, diketahui variabel Individual Interaction Capability (IIC) memiliki nilai koofisien beta yang positif sebesar 0.329 artinya jika variabel tersebut meningkat maka variabel dependen (Social Value Co-creation) akan meningkat. Nilai signifikasi atau p-value untuk pengaruh Individual Interaction Capability (IIC) secara parsial terhadap Social Value Co-creation (SVC) adalah sebesar 0.000, artinya lebih kecil dari 0.05. dan nilai t hitung sebesar 3.974, yang berarti lebih besar dari t tabel yaitu 1.973. Sehingga dapat disimpulkan bahwa terdapat pengaruh variabel independen (IIC) secara partial terhadap variabel dependen (SVC).

Kedua, variabel Relational Interaction Capability (RIC) memiliki nilai koofisien beta yang positif sebesar 0.164 artinya jika variabel tersebut meningkat maka variabel dependen (Social Value Co-creation) akan meningkat. Nilai signifikasi atau p-value untuk pengaruh Relational Interaction Capability (RIC) secara parsial terhadap Social Value Co-creation (SVC) adalah sebesar 0.049, artinya lebih kecil dari 0.05. dan nilai t hitung sebesar 1.977, yang berarti lebih besar dari t tabel yaitu 1.973. Sehingga dapat disimpulkan bahwa terdapat pengaruh variabel independen (RIC) secara partial terhadap variabel dependen (SVC).

Hasil penelitian ini mendukung hasil empirik penelitian sebelumnya seperti (Angelis et al., 2011; Grönroos, 2008; Saarijärvi et al., 2013) menyatakan bahwa saat berlangsungnya interaksi dengan pelanggan, karyawan harus memiliki kemampuan memahami pelanggan agar terjadi penciptaan nilai bersama. Ketika pelanggan merasa karyawan mampu memahami keinginan pribadi pelanggan mengenai perawatan yang ekslusif. Pelanggan akan berpartisipasi membantu karyawan meningkatkan layanan atau produk yang diberikan menjadi lebih mewah dan memiliki status prestise dari sebelumnya. Hal ini penting bagi perusahaan salon pada tingkat penciptaan nilai sosial dengan pelanggan melalui pemahaman lebih spesifik dari akan meningkatkan citra diri dan daya tarik produk atau layanan yang digunakan pelanggan

Madhavaram \& Hunt (2008) menyatakan bahwa ketika karyawan sedang melayani pelanggan, sebisa mungkin karyawan mampu untuk memulai komunikasi dengan pelanggan agar tidak terjadi masalah selama proses konsumsi. Hal ini dilakukan oleh pemasaran jasa atau layanan, karena untuk memenuhi permintaan pelanggan mengenai prestise merk produk perusahaan (Bian \& Veloutsou, 2007). Suatu prestise merk dapat mewakili sejauh mana kemampuan karyawan untuk menarik pelanggan, sehingga saat berlangsungnya interaksi yang menyenangkan antara karyawan dan pelanggan (Berry, 2002). Pelanggan akan ikut campur dalam membantu karyawan untuk meningkatkan citra merk dan prestise produk menjadi lebih baik dari sebelumnya. Hal ini, penting bagi perusahaan salon untuk memelihara tingkat penciptaan nilai sosial dengan pelanggan salon 
agar meningkatkan citra diri pada pelanggan melalui komunikasi yang mengarah pada daya tarik produk atau layanan yang digunakan

Model Persamaan 3:

$\mathrm{MP}=0.236 \mathrm{EVC}+0.316 \mathrm{SVC}+\mathrm{e}$

Berdasarkan perhitungan SPSS yeng telah dilakukan, variabel Emotional Value Cocreation (EVC) memiliki nilai koofisien beta yang positif sebesar 0.236 artinya jika variabel tersebut meningkat maka variabel dependen (Market Performance) akan meningkat. Nilai signifikasi atau p-value untuk pengaruh secara parsial atau sendiri-sendiri terhadap Market Performance (MP) adalah sebesar 0.013, artinya lebih kecil dari 0.05. dan nilai t hitung 2.502 yang berarti lebih besar dari t tabel yaitu 1.973. Sehingga dapat disimpulkan bahwa terdapat pengaruh variabel independen (EVC) secara parsial terhadap variabe dependen (MP).

Variabel Social Value Co-creation (SVC) memiliki nilai koofisien beta yang positif sebesar 0.316 artinya jika variabel tersebut meningkat maka variabel dependen (Market Performance) akan meningkat. Nilai signifikasi atau p-value untuk pengaruh secara parsial atau sendiri-sendiri terhadap Market Performance (MP) adalah sebesar 0.001, artinya lebih kecil dari 0.05. dan nilai nilai t hitung 3.353 yang berarti lebih besar dari t tabel yaitu 1.973. Sehingga dapat disimpulkan bahwa terdapat pengaruh variabel independen (SVC) secara parsial terhadap variabel dependen (MP).

Hasil penelitian ini mendukung hasil empirik penelitian sebelumnya seperti (Sweeney \& Soutar, 2001) bahwa ketika munculnya nilai emosional yang diharapkan pelanggan, mengenai perasaan nikmat, nyaman, dan betah pada suatu produk atau layanan. Pelanggan tidak akan segan untuk melakukan pelayanan kembali, karena pelayanan yang diberikan sesuai dengan nilai yang diinginkan. (Zhang et al., 2018). Suatu nilai yang ditawarkan oleh perusahaan akan menunjukkan kualitas pengalaman layanan (Aigninger, 2001). Hal ini juga berpengaruh saat pelanggan merasa partisipasinya membantu karyawan meningkatkan kenyamanan suatu produk atau layanan, lalu karyawan dapat menerapkannya dengan baik. Pelanggan akan merasa bahwa melakukan perawatan di salon tersebut merupakan pilihan yang tepat, sehingga berdampak pada pembelian ulang dan merekomendasikan pada konsumen lain untuk merasakan kepuasan salon langganan (Morgan, 2012).

Menurut Sánchez et al. (2006) saat pelanggan sudah merasakan suatu produk atau layanan yang meningkatkan citra dirinya, akan memiliki dampak yang kuat dan signifikan terhadap kepuasan. Pelanggan yang memiliki persepsi positif mengenai nilai sosial seperti citra merk akan memberikan efek langsung pada meningkatnya rasa puas pelanggan. (Li et al., 2019) menyatakan bahwa ketika pelanggan merasakan partisipasinya dalam membantu karyawan meningkatkan citra merk dan karyawan mampu melakukannya dengan baik, akan membuat pelanggan merasa terlibat dalam proses produksi jasa sehingga semua konsekuensi dari hasilnya bersedia dipertanggungjawabkannya. Hal ini akan berdampak pada keinginan pelanggan dalam mendorong konsumen lain untuk ikut menggunakan jasa salon yang sama.

\section{SIMPULAN DAN REKOMENDASI}

\subsection{Simpulan}

Studi ini telah berhasil menjawab pertanyaan penelitian tentang bagaimana meningkatkan marketing performance jasa salon kecantikan melalui interaction capability dan value co-creation. 
Berdasarkan analisis data yang telah dilakukan, dan pembahasan yang telah dikemukakan, maka dapat ditarik kesimpulan bahwa Individual Interaction Capability menjadi variabel yang berpengaruh positif dan signifikan terhadap Emotional Value Co-creation. Artinya, semakin positif pelanggan salon kecantikan mempersepsikan bahwa karyawan memiliki kemampuan memahami kebutuhan pribadi mereka, maka pelanggan lebih bersedia berpartisipasi membantu karyawan salon dengan jalan memberikan masukan mengenai produk atau layanan yang lebih aman dan nyaman.

Selain itu, variabel Individual Interaction Capability juga terbukti berpengaruh positif signifikan terhadap Social Value Co-creation. Temuan ini dapat dimaknai bahwa, semakin positif pelanggan salon kecantikan mempersepsikan karyawan salon memiliki kemampuan memahami kebutuhan mereka secara personal, maka pelanggan akan lebih bersedia terlibat dalam kreasi nilai bersama dengan karyawan dengan cara membantu memberikan masukan dalam meningkatkan prestise produk atau layanan yang lebih baik daripada sebelumnya. Melalui komunikasi antara karyawan dan pelanggan, ide dan informasi dari pelanggan menjadi lebih berbobot, dipercaya dan lebih otentik daripada hanya dari perusahaan (Trusov et al., 2009).

Studi ini juga melibatkan variabel Relational Interaction Capability dalam meningkatkan value emotional dan social value co creation. Hubungan antar variabel tersebut telah terbukti positif dan signifikan. Temuan ini mempunyai makna bahwa, Ketika pelanggan salon kecantikan mempunyai persepsi positif terhadap kemampuan karyawan salon dalam melakukan komunikasi dua arah dengan pelanggan, maka pelanggan semakin ingin terlibat dalam membantu karyawan salon memberikan masukan mengenai produk atau layanan yang lebih aman dan nyaman. Keyakinan pelanggan salon terhadap kemampuan karyawan dalam berkomunikasi juga membuat pelanggan tidak ragu dalam memberikan masukan tentang bagaimana meningkatkan citra dirinya ketika pelanggan mengkonsumsi jasa salon. Pelanggan yang merasakan citra dirinya meningkat, akan memiliki dampak yang kuat dan signifikan terhadap kepuasan (Sánchez et al., 2006).

Melibatkan pelanggan dalam kreasi nilai emosional dan sosial secara bersama, akan lebih meningkatkan engagement antara pelanggan dan karyawan fronline. Take and give pengetahuan antara keduanya, akan menciptakan rasa dihargai sehingga kepuasannya meningkat. Kebutuhan dan keinginan pelanggan salon yang terpenuhi dengan baik, akan menguatkan keinginannnya untuk menjalin hubungan jangka panjang dengan salon yang sama. Pelanggan tidak akan segan untuk kembali menggunakan jasa yang sama, ketika pelayanan yang diberikan sesuai dengan nilai yang diinginkan (Zhang et al., 2018).

Dalam meningkatkan kemajuan perusahaan. Adapun saran yang diberikan diantaranya Individual Interaction Capability merupakan variabel yang paling berpengaruh pada Emotional Value Co-creation dan Social Value Co-creation, sehingga perlu diketahui kepekaan karyawan dalam memahami sensitivitas pelanggan memiliki pengaruh tinggi pada variabel Emotional Value Co-creation dan Social Value Co-creation.

Untuk meningkatkan peran Relational Interaction Capability dalam meningkatkan Emotional Value Co-creation dan Social Value Co-creation, perusahaan dapat meningkatkan kemampuan karyawan dalam menjalin hubungan dengan pelanggan melalui komunikasi dua arah memiliki pengaruh tinggi pada variabel Emotional Value Co-creation dan Social Value Cocreation. Peningkatan pemahaman situasi pribadi pelanggan dapat meningkatkan intensitas Emotional Value Co-creation dan Social Value Co-creation. 
Emotional Value Co-creation berpengaruh pada Market Performance, melalui kenyamanan pada suatu produk atau layanan yang diberikan karyawan memiliki pengaruh cukup tinggi pada variabel Market Performance. Hal ini diharapkan, peningkatan rasa aman dan nyaman selama proses layanan akan meningkatkan kepuasan pelanggan.

Social Value Co-creation sangat berpengaruh pada Market Performance, sehingga melalui nilai sosial seperti prestise produk akan berpengaruh cukup tinggi pada variabel Market Performance. Hal ini diharapkan, dengan melalui peningkatan indikator citra merk suatu layanan akan meningkatkan pengaruh Market Performance.

Studi ini memiliki beberapa keterbatasan, diantaranya adalah: nilai $\mathrm{R}$ square yang masih masuk dalam kategori sedang, yaitu sebesar 0.39, sehingga masih membuka peluang bagi peneliti selanjutnya untuk menyempurnakannya dengan mengambil variabel independen yang berbeda jika ingin melihat pengaruhnya pada marketing performance sebuah jasa salon. Selain itu, kemungkinan terjadinya response bias akibat dari kelemahan penggunaan kuesioner.

\subsection{Agenda Penelitian Selanjutnya}

Peneliti dapat mencari faktor lain yang dapat mempengaruhi Value Co-creation, baik sebagai variabel independen baru, variabel dengan pengaruh mediasi maupun moderasi serta dapat juga berupa variabel dependen baru. Selain itu, peneliti dapat mengembangkan hasil penelitian ini dengan melakukan uji komparatif. Uji komparatif dapat dilakukan dengan mengangkat objek penelitian maupun wilayah penelitian yang berbeda.

\section{DAFTAR PUSTAKA}

Aigninger, K. (2001). Measuring the Intensity of Quality Competition in Industries. Austrian Economic Quarterly, 6(2), 73-101.

Angelis, J., Conti, R., Cooper, C., \& Gill, C. (2011). Building a high-commitment lean culture. Journal of Manufacturing Technology Management, 22(5), 569-586.

Baker, W. E., \& Sinkula, J. M. (2005). Market Orientation and the New Product Paradox. Journal of Product Innovation Management, 22(3), 483-502.

Barlow, J., \& Maul, D. (2000). Emotional Value: Creating Strong Bonds with Your Customers. Berrett-Koegler Publishers.

Barney, J. B. (2001). Resource-based theories of competitive advantage: A ten-year retrospective on the resource-based view. Journal of Management, 27(6), 643-650.

Berry, L. L. (2002). Relationship Marketing of Services Perspectives from 1983 and 2000. Journal of Relationship Marketing, 1(1), 59-77.

Bian, X., \& Veloutsou, C. (2007). Consumers' attitudes regarding non-deceptive counterfeit brands in the UK and China. Journal of Brand Management, 14(3), 211-222.

Branimir, P. I., \& Zelimir, M. P. (2012). The influence of service-dominant orientation of small firms on its growth. African Journal of Business Management, 6(45), 11202-11205.

Buana, Y., Isanawikrama, I., Hutomo, E. J., \& Kurniawan, Y. J. (2019). Konseptualisasi Value Co-Creation Dalam Konteks Customer To Customer. Jurnal Pengabdian Dan Kewirausahaan, 3(1), 44-55.

Ferdinand, A. (2000). Structural Equation Modelling dalam Penelitian Manajemen. Semarang: Penerbit Universitas Diponegoro. 
Forza, C., \& Salvador, F. (2002). Managing for variety in the order acquisition and fulfilment process: The contribution of product configuration systems. International Journal of Production Economics, 76(1), 87-98.

Franke, N., \& Piller, F. (2004). Value creation by toolkits for user innovation and design: The case of the watch market. Journal of Product Innovation Management, 21(6), 401-415.

Frow, P., \& Payne, A. (2011). A stakeholder perspective of the value proposition concept. European Journal of Marketing, 45(1), 223-240.

Ghozali, I. (2008). Aplikasi Analisis Multivariate dengan Program SPSS. Semarang: Badan Penerbit Universitas Diponegoro.

Grönroos, C. (2008). Service logic revisited: Who creates value? And who co-creates? European Business Review, 20(4), 298-314.

Grönroos, C., \& Ravald, A. (2011). Service as business logic: Implications for value creation and marketing. Journal of Service Management, 22(1), 5-22.

Hair, J. F., Black, W. C., Babin, B. J., Anderson, R. E., \& Tatham, R. (2006). Multivariate Data Analysis. NJ: Pearson Prentice Hall.

Harmeling, C. M., Moffett, J. W., Arnold, M. J., \& Carlson, B. D. (2017). Toward a theory of customer engagement marketing. Journal of the Academy of Marketing Science, 45(3), $312-335$.

Hogel, J., \& Brown, J. S. (2005). The Only Sustainable Edge: Why Business Strategy Depends on Productive Friction and Dynamic Specialization. Boston: Harvard Business School Press.

Hollebeek, L. D., Conduit, J., \& Brodie, R. J. (2016). Strategic drivers, anticipated and unanticipated outcomes of customer engagement. Journal of Marketing Management, 32(5-6), 393-398.

Homburg, C., \& Jensen, O. (2007). The thought worlds of marketing and sales: Which differences make a difference? Journal of Marketing, 71(3), 124-142.

Ikkala, T., \& Lampinen, A. (2015). Monetizing Network Hospitality. CSCW'15 Proceedings of the 18th ACM Conference on Computer Supported Cooperative Work \& Social Computing, 1033-1044.

Karpen, I. O., Bove, L. L., \& Lukas, B. A. (2012). Linking Service-Dominant Logic and Strategic Business Practice: A Conceptual Model of a Service-Dominant Orientation. Journal of Service Research, 15(1), 21-38.

Karpen, I. O., Bove, L. L., Lukas, B. A., \& Zyphur, M. J. (2015). Service-dominant orientation: Measurement and impact on performance outcomes. Journal of Retailing, 91(1), 89-108.

Kreitner, R., \& Angelo, K. (2003). Perilaku Organisasi (Organization Behavior). Jakarta: Salemba Empat.

Li, X., Chan, K. W., \& Kim, S. (2019). Service with emoticons: How customers interpret employee use of emoticons in online service encounters. Journal of Consumer Research, 45(5), 973 987.

Lichtenstein, B. B., \& Lumpkin, G. T. (2008). The role of organizational learning in the opportunity recognition process. Entrepreneurial Learning: Conceptual Frameworks and Applications, 29(4), 95-119.

Lusch, R. F., Vargo, S. L., \& O’Brien, M. (2007). Competing through service: Insights from service-dominant logic. Journal of Retailing, 83(1), 5-18. 
Madhavaram, S., \& Hunt, S. D. (2008). The service-dominant logic and a hierarchy of operant resources: Developing masterful operant resources and implications for marketing strategy. Journal of the Academy of Marketing Science, 36(1), 67-82.

Maulina, E., \& Sari, M. N. (2017). Policies and Business Strategies of Women Entrepreneurs: Study on Beauty Business Nadisse Salon. Jurnal AdBispreneur, 2(1), 69-78.

Merz, M. A., He, Y., \& Vargo, S. L. (2009). The evolving brand logic: A service-dominant logic perspective. Journal of the Academy of Marketing Science, 37(3), 328-344.

Morgan, N. A. (2012). Marketing and business performance. Journal of the Academy of Marketing Science, 40(1), 102-119.

Morgan, N. A., Slotegraaf, R. J., \& Vorhies, D. W. (2009). Linking marketing capabilities with profit growth. International Journal of Research in Marketing, 26(4), 284-293.

Mutiah. (2020). Pengaruh Harga dan Kualitas Porduk terhadap Keputusan Pembelian Produk (Studi Kasus pada KOonsumen Produk PT.HNI HPAI). Journal Of Management, Accounting, Economic and Business, 01(02), 56-70.

Pan, H. (2020). Online Community Value Co-creation: Differences in Firms' Strategies and Moderating Conditions. Online Information Review, 44(3), 645-669.

Payne, A., \& Frow, P. (2013). Strategic Customer Management: Integrating Relationship Marketing and CRM. Cambridge UK : Cambridge University Press.

Payne, A., Storbacka, K., \& Frow, P. (2008). Managing the co-creation of value. Journal of the Academy of Marketing Science, 36(1), 83-96.

Payne, A., Storbacka, K., Frow, P., \& Knox, S. (2009). Co-creating brands: Diagnosing and designing the relationship experience. Journal of Business Research, 62(3), 379-389.

Prahalad, \& Ramaswamy, V. (2000). Co-Opting Customer Competence. Harvard Business Review, 16(2), 79-87.

Prahalad, \& Ramaswamy, V. (2003). The New Frontier of Experience Innovation. MITSloan Management Review, 44(4), 12-18.

Prahalad, \& Ramaswamy, V. (2004). Co-creating unique value with customers. Strategy \& Leadership, 32(3), 4-9.

Rahi, S. (2017). Research Design and Methods: A Systematic Review of Research Paradigms, Sampling Issues and Instruments Development. International Journal of Economics \& Management Sciences, 06(02), 1-5.

Ramaswamy, V., \& Ozcan, K. (2018). What is co-creation? An interactional creation framework and its implications for value creation. Journal of Business Research, 84(November 2017), 196-205.

Ranjan, K. R., \& Read, S. (2016). Value co-creation: concept and measurement. Journal of the Academy of Marketing Science, 44(3), 290-315.

Saarijärvi, H., Kannan, P. K., \& Kuusela, H. (2013). Value co-creation: theoretical approaches and practical implications. European Business Review, 25(1), 6-19.

Saeko, A. N., Chuntarung, P., \& Thoumrungroje. (2012). The Impact of Integrated Marketing Strategy on Mareting Performance: An Em-pirical Evidence From Exporting Business in Thailand. International Journal of Business Strategy, 12(4), 56-73. 
Sahi, G. K., Sekhon, H. S., \& Quareshi, T. K. (2016). Role of trusting beliefs in predicting purchase intentions. In International Journal of Retail and Distribution Management (Vol. 44, Issue 8), 860-880

Sambyal, N., Saini, P., \& Syal, R. (2020). Microvascular Complications in Type-2 Diabetes: A Review of Statistical Techniques and Machine Learning Models. Wireless Personal Communications, 115(1), 1-18.

Sánchez, J., Callarisa, L., Rodríguez, R. M., \& Moliner, M. A. (2006). Perceived value of the purchase of a tourism product. Tourism Management, 27(3), 394-409.

Smith, J. B., \& Colgate, M. (2007). Customer value creation: A practical framework. Journal of Marketing Theory and Practice, 15(1), 7-23.

Sweeney, J. C., \& Soutar, G. N. (2001). Consumer perceived value: The development of a multiple item scale. Journal of Retailing, 77, 2013-2220.

Syam, N. B., \& Pazgal, A. (2013). Co-creation with production externalities. Marketing Science, 32(5), 805-820.

Tjiptono, F. (2005). Pemasaran Jasa (pertama). Malang: Bayu Media Publishing.

Trusov, M., Bucklin, R. E., \& Pauwels, K. (2009). Effects of word-of-mouth versus traditional marketing: Findings from an internet social networking site. Journal of Marketing, 73(5), 90-102.

Vargo, S. L., \& Lusch, R. F. (2004). Evolving To A New Dominant Logic Of Markteing. Journal of Marketing, 68(January), 1-17.

Vargo, S. L., \& Lusch, R. F. (2014). Service-Dominant Logic: Premises, Perspectives, Possibilities. Cambridge, UK: Cambridge University Press.

Vargo, S. L., \& Lusch, R. F. (2016). Institutions and axioms: an extension and update of servicedominant logic. Journal of the Academy of Marketing Science, 44(1), 5-23.

Vargo, S. L., Lusch, R. F., Akaka, M. A., \& He, Y. (2010). Service Dominant Logic. Review of Marketing Research, 6, 125-167.

Vargo, S. L., Maglio, P. P., \& Akaka, M. A. (2008). On value and value co-creation: A service systems and service logic perspective. European Management Journal, 26(3), 145-152.

Vega-Vazquez, M., Revilla-Camacho, M. Á., \& Cossío-Silva, F. J. (2013). The value co-creation process as a determinant of customer satisfaction. Management Decision, 51(10), 19451953.

Voss, G. B., \& Voss, Z. G. (2000). Strategic orientation and firm performance in an artistic environment. Journal of Marketing, 64(1), 67-83.

Zhang, T. C., Jahromi, M. F., \& Kizildag, M. (2018). Value co-creation in a sharing economy: The end of price wars? International Journal of Hospitality Management, 71(November 2017), $51-58$. 